\title{
The Free Cesarian in the Health District of Bougouni
}

\author{
Cheickna Sylla $1{ }^{12}$, Soumana Oumar Traoré ${ }^{2,3}$, Sitapha Dembele 4 , Seydou Z. Dao5, \\ Lassana Togola1, Amadou Boucoum ${ }^{2,6}$, Seydou Fanée,6, Ibrahima Teguetéz,6, \\ Youssouf Traoréé,6, Niani Mounkoro ${ }^{2,6}$
}

\begin{abstract}
${ }^{1}$ Department of Obstetrics and Gynecology, Koutiala Reference Health Centre, Sikasso, Mali
${ }^{2}$ Faculty of Medicine and Odontostomatology, University of Science, Technology and Technology of Bamako, Bamako, Mali ${ }^{3}$ Department of Gynecology and Obstetrics, Reference Health Centre of Commune V, Bamako, Mali

${ }^{4}$ Department of Obstetrics and Gynecology, Kayes Hospital, Kayes, Mali

${ }^{5}$ Department of Gynecology and Obstetrics, Commune II Reference Health Centre, Bamako, Mali

${ }^{6}$ Department of Gynecology and Obstetrics, Gabriel Touré University Hospital, Bamako, Mali

Email: *scheickylla@yahoo.fr
\end{abstract}

How to cite this paper: Sylla, C., Traoré, S.O., Dembele, S., Dao, S.Z., Togola, L., Boucoum, A., Fané, S., Tegueté, I., Traoré, Y. and Mounkoro, N. (2020) The Free Cesarian in the Health District of Bougouni. Open Journal of Obstetrics and Gynecology, 10, 1233-1245.

https://doi.org/10.4236/ojog.2020.1090115

Received: August 12, 2020

Accepted: September 20, 2020

Published: September 23, 2020

Copyright $\odot 2020$ by author(s) and Scientific Research Publishing Inc. This work is licensed under the Creative Commons Attribution International License (CC BY 4.0).

http://creativecommons.org/licenses/by/4.0/

\section{(c) (i) Open Access}

\begin{abstract}
Purpose: The purpose of this study was to assess the impact of free caesarean section on maternal-fetal prognosis. Materials and Methods: This was a descriptive, cross-sectional, comparative analytical study of one year of non-free caesarean section and three years of free with retrospective data collection. Our study took place from January 1, 2004 to December 31, 2004 and from January 1, 2007 to December 31, 2009. Results: Caesarean section completion rates are $1.28 \%, 1.30 \%, 1.53 \%, 1.32 \%$ respectively in 2004, 2007, 2008, 2009. The average age was 27 years with extremes of 15 to 40 years. The peak of evacuations was recorded in 2007 with a rate of $89.4 \%$ and the peak of direct admissions in 2009 with a rate of $14.9 \%$. An adequate means of transport was used in $77.20 \%$. In $22.80 \%$ of cases an inadequate means was used. The indications of caesarean sections were dominated by preeclampsia 211/1045 caesarean section followed by acute fetal suffering 179/1045; 86/1045; placenta previa 64/1045; presentations of the shoulder i.e. 53/1045; pre-rupture syndrome 44/1045; retro-placental hematoma 27/1045. In terms of maternal prognosis: we noted maternal deaths with a rate of $2.4 \%, 2.4 \%, 4.3 \%, 0.4 \%$ respectively in 2004, 2007, 2008, 2009. And stillbirth rates were $17.6 \%, 22.4 \%$, $27.4 \%, 21.7 \%$ respectively in $2004,2007,2008,2009$. The average length of hospitalization was 10 days. Conclusion: Free caesarean section would be a factor in improving the maternal-fetal prognosis.
\end{abstract}




\section{Keywords}

Caesarean Section, Free of Charge, Frequency Indications, Prognosis

\section{Introduction}

Caesarean section is defined as an obstetrical technique consisting of surgical incision of the abdominal wall and uterus for rapid evacuation of the conceived product [1]. With an estimated maternal mortality rate of 1020 deaths per 100,000 live births (WHO, 1990) [2], West Africa is the region most affected. This increase is due to low coverage of maternal health needs. In Mali, the direct estimate of the maternal mortality rate in 2006 was 464 deaths per 100,000 live births according to EDSM IV, despite efforts to reduce maternal mortality.

WHO in 1985 set an optimal range of caesarean section rates between $10 \%$ and $15 \%$ for all countries in the world [2]. Considered from the $19^{\text {th }}$ to the $20^{\text {th }}$ century as a perilous, deadly undertaking in the living woman [3], the practice of caesarean section would be a factor in improving obstetric care. Its indications are increasingly spread over several obstetric pathologies resulting in an increase in its frequency over the last two decades.

In 1987, these rates reached $25 \%$ in the USA and $16 \%$ in Germany Federal [4]. In the different regions of Mali for the period 2002, we noted: $0.1 \%$ caesarean section in Koulikoro and Kidal; $0.2 \%$ in Timbuktu; 0.3\% in Kayes; 0.4\% in Mopti and Gao; $0.6 \%$ in Ségou; $0.9 \%$ in Sikasso and Bamako is alone in the lead with $3.7 \%$ of caesarean deliveries [5]. More than four million newborns disappear each year, most often as a result of under-care pregnancies and deliveries. The perinatal mortality rate according to EDSM IV 2006 is 46 per 1000 births.

In developing countries such as Mali, resources are limited to cover all obstetric needs. Maternal and neonatal mortality remains a serious concern. The rapid management of obstetric emergencies can influence this prognosis, but the socio-economic conditions of most of our populations do not provide this care. The "freeness" of caesarean section may well be a factor in mitigating maternal and neonatal mortality by improving access to this intervention.

To reinforce previous strategies to reduce maternal-fetal mortality, the Government of Mali decided on 23 June 2005 to institute the "free" of caesarean section in public hospitals, reference health centres in circles, municipalities in Bamako district and institutions of the armed health service [6].

The Bougouni Reference Health Centre, which is affected by these measures, has had its system reorganized to meet the needs of the population. So after the government decided that the caesarean section should be free of charge, we thought it was important to evaluate its implementation in our service.

\section{Objectives}

The purpose of this study was to assess the impact of free caesarean section on 
maternal-fetal prognosis; Determine the prevalence of caesarean section Describe the socio-demographic characteristics of patients Determine the indications of caesarean section; determine the maternal-fetal prognosis determine the difficulties in free caesarean section.

\section{Materials and Methods}

This was a descriptive, cross-sectional, comparative analytical study of one year of non-free caesarean section and three years of free caesarean section with a retrospective collection of data at the reference health centre in Bougouni, Sikasso, Mali. Our study took place from January 1, 2004 to December 31, 2004 and from January 1, 2007 to December 31, 2009. We left the year 2005 or start of the free caesarean section and the year 2006 for difficulties related to the start-up. The study population: These are the parturients admitted to the delivery room whether they came on their own, evacuated or referred from peripheral health facilities. Inclusion criteria: We included in our study all participants admitted to the reference health centre and who gave birth by caesarean section. Non-inclusion criteria: we did not include in the study all caesarean sections performed in other structures and having been admitted secondary to the reference health centre for whatever reason.

The data collection technique: the data was collected on a fact sheet filled out from the information on the files of the parturients; birth records and operational reports. The technique consisted of reading the media generated and recording the data on the fact sheet. The variables studied were: age, method of admission, mode of transport, prenatal consultation, distance travelled, route of delivery, caesarean section indications (per and operative settings); the availability of the kit, the rate of caesarean section, the procedures associated with the per-operative, the length of hospital stay; complications, maternal-fetal prognosis. The limitations of the study: taking into account the difficulties of starting free caesarean section, the years 2005 and 2006 could not be taken into account in the study. Due to the quality of the retrospective study, we were unable to determine the transport time. Computer data analysis: Data was captured and analyzed using Microsoft Word 2007 and SPSS 12.O software. The statistical tests used were the Khi2, P-5\% considered significant.

\section{Results}

Cesarean section completion rates were $1.28 \%, 1.30 \%, 1.53 \%, 1.32 \%$ respectively in $2004,2007,2008,2009$. The frequency of caesarean section compared to vaginal deliveries was $25.86 \%, 25.49 \%, 33.59 \%, 31.45 \%$ respectively in 2004,2007 , 2008,2009 . The average age was 27 years with extremes of 15 to 40 years. Table 1 shows us the age and birth route of the parturients.

Figure 1 represents the frequency of caesarean sections compared to vaginal deliveries at the Bougouni Reference Health Centre, Sikasso, Mali from 2004 to 2009. 
Reference/evacuation, means of transport and distance travelled: The peak of evacuations was recorded in 2007 with a rate of $89.4 \%$ and the peak of direct admissions in 2009 with a rate of $14.9 \%$. An adequate means of transport (ambulance) was used in $77.20 \%$ and an inadequate means in $22.80 \%$ (taxis, motorbikes, bicycles). The shortest distance was $1 \mathrm{~km}$ and the longest $150 \mathrm{~km}$. The average distance covered was $75.45 \mathrm{~km}$. Table 2 shows us the distribution of parturients

Table 1. Distribution of parturients by age and route of delivery of parturients at the Bougouni Reference Health Centre, Sikasso, Mali from 2004 to 2009.

\begin{tabular}{ccccccc}
\hline \multicolumn{1}{c}{ Years } & $\mathbf{2 0 0 4}$ & $\mathbf{2 0 0 7}$ & $\mathbf{2 0 0 8}$ & $\mathbf{2 0 0 9}$ & $\mathrm{Khi}^{2}$ & $\mathbf{p}$ \\
\hline$\leq 19$ ans & $34(16.2 \%)$ & $50(20.3 \%)$ & $58(19.1 \%)$ & $50(18.7 \%)$ & 4100.01 & 0.96 \\
$19-25$ & $96(45.7 \%)$ & $84(34.1 \%)$ & $90(29.7 \%)$ & $104(38.8 \%)$ & 1.11 & 0.29 \\
$26-35$ & $61(29.0 \%)$ & $81(32.9 \%)$ & $123(40.6 \%)$ & $91(34.0 \%)$ & 0.35 & 0.55 \\
$>35$ & $19(09.0 \%)$ & $31(12.6 \%)$ & $32(10.6 \%)$ & $23(08.6 \%)$ & $<5$ & 0.74 \\
Delivery & & & & & & \\
Low way & $602(74.14 \%)$ & $719(74.51 \%)$ & $599(66.41 \%)$ & $584(68.55 \%)$ & & \\
Cesarean & $210(25.86 \%)$ & $246(25.49 \%)$ & $303(33.59 \%)$ & $268(31.45 \%)$ & & \\
\hline
\end{tabular}

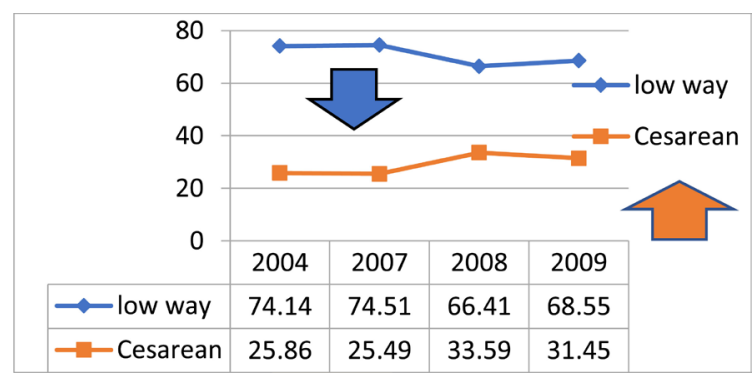

Figure 1. The frequency of caesarean sections compared to vaginal deliveries at the Bougouni Reference Health Centre, Sikasso, Mali from 2004 to 2009.

Table 2. Distribution of parturients by method of admission and mode of transport used at the Bougouni Reference Health Centre, Sikasso, Mali from 2004 to 2009.

\begin{tabular}{|c|c|c|c|c|c|c|}
\hline Mode admission & 2004 & 2007 & 2008 & 2009 & $\mathrm{Khi}^{2}$ & $\mathrm{p}$ \\
\hline Evacuations & $125(59.5 \%)$ & $220(89.4 \%)$ & $212(70.0 \%)$ & $132(49.3 \%)$ & 2.56 & 0.10 \\
\hline References & $57(27.1 \%)$ & $11(04.5 \%)$ & $55(18.2 \%)$ & $96(35.8 \%)$ & 1.36 & 0.24 \\
\hline Direct admission & $28(13.3 \%)$ & $15(06.1 \%)$ & $36(11.9 \%)$ & $40(14.9 \%)$ & 0.83 & 0.84 \\
\hline \multicolumn{7}{|l|}{ Transportation } \\
\hline Ambulance & $163(77.6 \%)$ & $221(89.8 \%)$ & $262(86.5 \%)$ & $207(77.2 \%)$ & 0.001 & 0.99 \\
\hline Taxis & $30(14.3 \%)$ & 10 (04.1\%) & $24(07.9 \%)$ & $42(15.7 \%)$ & & \\
\hline Motorcycle & $12(05.7 \%)$ & $9(03.7 \%)$ & $12(04.0 \%)$ & $16(06.0 \%)$ & & \\
\hline Bicycles & $5(02.4 \%)$ & $6(02.4 \%)$ & $5(01.7 \%)$ & $3(01.1 \%)$ & & \\
\hline
\end{tabular}


by method of admission and means of transport used. Table 3 shows the distance travelled from the community health centre in the reference/evacuation community to the reference health centre in Bougouni.

Prenatal consultations: Pregnant women who had carried out between 1 to 3 consultations were the majority during the 4 years of study with a peak of $80.20 \%$ in 2008 and the rate of those of pregnant women who had not performed any antenatal consultations of $26.10 \%$ in 2009 . Table 4 refers to the distribution of pregnant women based on the number of antenatal visits performed.

The availability of caesarean kits at the time of the caesarean section indication: the caesarean kit peak not available at the time of the caesarean section was found in 2007 with $6.90 \%$ and that of the caesarean kit available at the time of the caesarean section was noted in 2008 with an availability rate of $97 \%$. Table 5 shows us the availability of the caesarean kit at the time of the caesarean section.

Cesarean section indications: were dominated by preeclampsia 211/1045 caesarean section followed by acute fetal suffering 179/1045; 86/1045; placenta

Table 3. Distance travelled during referrals/evacuations from the community health centre in the locality of reference or evacuation centre at the Bougouni Reference Health Centre, Sikasso, Mali from 2004 to 2009.

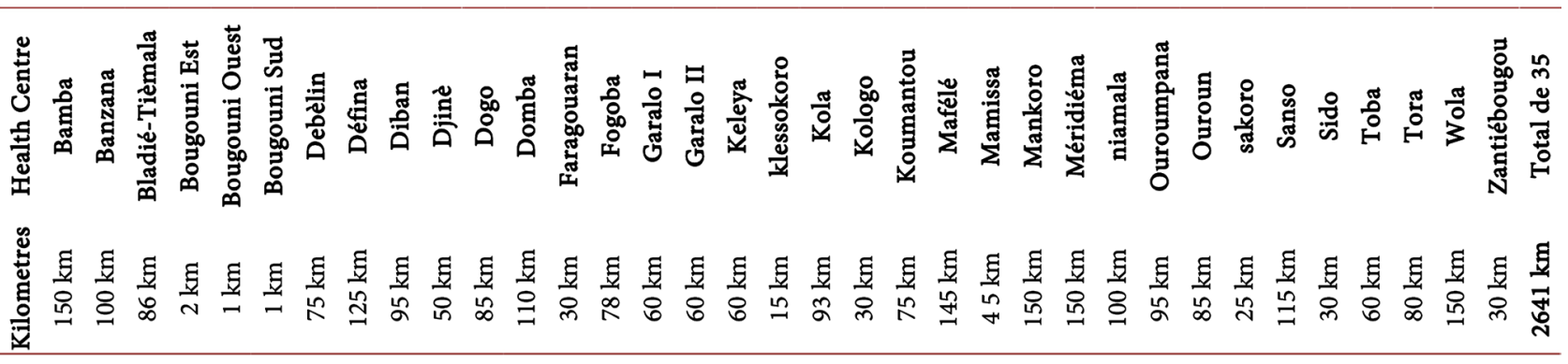

Table 4. Breakdown of pregnant women based on the number of antenatal visits at the Bougouni Reference Health Centre, Sikasso, Mali from 2004 to 2009.

\begin{tabular}{|c|c|c|c|c|c|c|}
\hline $\begin{array}{l}\text { Prenatal } \\
\text { consultation }\end{array}$ & 2004 & 2007 & 2008 & 2009 & $\mathrm{Khi}^{2}$ & $\mathrm{p}$ \\
\hline 0 & $42(20.0 \%)$ & $82(33.3 \%)$ & $59(19.5 \%)$ & $70(26.1 \%)$ & 0.65 & 0.41 \\
\hline 1 à 3 & $165(78.6 \%)$ & $163(66.3 \%)$ & $243(80.2 \%)$ & $194(72.4 \%)$ & 2.10 & 0.14 \\
\hline 4 et plus & $3(01.4 \%)$ & $1(00.4 \%)$ & $1(00.3 \%)$ & $4(01.5 \%)$ & 0.34 & 0.85 \\
\hline Total & $210(100.0 \%)$ & $246(100.0 \%)$ & 303 (100.0\%) & $268(100.0 \%)$ & & \\
\hline
\end{tabular}

Table 5. Availability of caesarean section kit at the time of caesarean section at the Bougouni Reference Health Centre, Sikasso, Mali from 2004 to 2009.

\begin{tabular}{|c|c|c|c|c|c|c|}
\hline $\begin{array}{l}\text { Caesarean } \\
\text { kit }\end{array}$ & 2004 & 2007 & 2008 & 2009 & $\mathrm{Khi}^{2}$ & $\mathrm{p}$ \\
\hline Yes & 201 (95.7\%) & $229(93.1 \%)$ & $294(97.0 \%)$ & $258(96.3 \%)$ & 0.10 & 0.74 \\
\hline No & $9(04.3 \%)$ & $17(06.9 \%)$ & $9(03.0 \%)$ & $10(03.7 \%)$ & 0.23 & 0.18 \\
\hline Total & $210(100.0 \%)$ & $246(100.0 \%)$ & $303(100.0 \%)$ & $268(100.0 \%)$ & & \\
\hline
\end{tabular}


previa 64/1045; presentations of the shoulder i.e. 53/1045; pre-rupture syndrome 44/1045; retro-placental hematoma 27/1045. We noted cases of uterine rupture whose rate varied during the four years of study without decreasing (Table 6).

The average length of hospitalization for caesarean patients represented in Table 7 was 10 days with extremes of 5 to 25 days.

The surgical procedures were simple in $90 \%$ of our patients. However, infectious complications of endometritis and parietal suppurations were noted. Thus in 2004 , the rate of endometritis was $2.90 \%$ and that of parietal suppuration was

Table 6. Caesarean section indications at the Bougouni Reference Health Centre, Sikasso, Mali from 2004 to 2009.

\begin{tabular}{|c|c|c|c|c|}
\hline Years & 2004 & 2007 & 2008 & 2009 \\
\hline Placental retro hematoma & $9(04.3 \%)$ & $5(00.8 \%)$ & $8(02.6 \%)$ & $5(01.9 \%)$ \\
\hline Placenta previa & $16(07.6 \%)$ & $13(05.3 \%)$ & $30(09.9 \%)$ & $15(05.6 \%)$ \\
\hline Acute fetal suffering & $33(15.7 \%)$ & $34(13.8 \%)$ & $62(20.5 \%)$ & $50(18.7 \%)$ \\
\hline Bi-scar uterus & $9(04.3 \%)$ & $5(02.0 \%)$ & $19(06.3 \%)$ & $20(07.5 \%)$ \\
\hline Extended work & $23(11.0 \%)$ & $20(08.1 \%)$ & $18(05.9 \%)$ & $25(09.3 \%)$ \\
\hline Immature pelvis & $14(06.7 \%)$ & $0(00.0 \%)$ & $1(00.3 \%)$ & $12(04.5 \%)$ \\
\hline Generally shrunken basin & $7(03.3 \%)$ & $11(04.5 \%)$ & $10(03.3 \%)$ & $13(04.9 \%)$ \\
\hline Uterine rupture & $16(07.6 \%)$ & $22(08.9 \%)$ & $30(09.9 \%)$ & $26(09.7 \%)$ \\
\hline Transverse presentation & $8(03.8 \%)$ & $17(06.9 \%)$ & $12(04.0 \%)$ & $16(06.0 \%)$ \\
\hline Pre-breakup syndrome & $10(04.8 \%)$ & $11(04.5 \%)$ & $13(04.3 \%)$ & $10(03.7 \%)$ \\
\hline Other indications: & $62(29.5 \%)$ & $111(45.1 \%)$ & $98(32.3 \%)$ & $7226.9 \%)$ \\
\hline Pre-eclampsia and eclampsia & $39(18.6 \%)$ & $69(28.0 \%)$ & $56(18.5 \%)$ & $47(17.5 \%)$ \\
\hline Introducing members & $8(03.8 \%)$ & $27(11.0 \%)$ & $25(08.5 \%)$ & $17(06.3 \%)$ \\
\hline Loaded obstetric history & $15(07.1 \%)$ & $15(06.1 \%)$ & $17(05.6 \%)$ & $8(03.0 \%)$ \\
\hline Total & $210(100 \%)$ & $246(100 \%)$ & $303(100 \%)$ & $268(100 \%)$ \\
\hline
\end{tabular}

Table 7. Average length of hospitalization for caesarean sections at the Bougouni Reference Health Centre, Sikasso, Mali from 2004 to 2009.

\begin{tabular}{|c|c|c|c|c|c|c|}
\hline Duration & 2004 & 2007 & 2008 & 2009 & $\mathrm{Khi}^{2}$ & $\mathrm{p}$ \\
\hline$\leq 7$ & $161(76.7 \%)$ & $205(83.3 \%)$ & $251(82.8 \%)$ & $231(86.2 \%)$ & 6.15 & 0.01 \\
\hline $8-14$ & $47(22.4 \%)$ & $35(14.2 \%)$ & $40(13.2 \%)$ & $32(11.9 \%)$ & 1.47 & 0.22 \\
\hline$>14$ & $2(01.0 \%)$ & $6(02.4 \%)$ & $12(04.0 \%)$ & $5(01.9 \%)$ & 1.61 & 0.29 \\
\hline Total & 210 (100.0\%) & $246(100.0 \%)$ & $303(100.0 \%)$ & 268 (100.0\%) & & \\
\hline
\end{tabular}


9\%, whereas in 2009 the rate of endometritis was $1.5 \%$ and that of parietal suppuration was $7.1 \%$.

Maternal mortality: We have noted maternal deaths with a rate of $2.4 \%$, $2.4 \%, 4.3 \%, 0.4 \%$ respectively in $2004,2007,2008,2009$. And stillbirth rates were $17.6 \%, 22.4 \%, 27.4 \%, 21.7 \%$ respectively in $2004,2007,2008$, 2009. Table 8, Figure 2 and Figure 3 show maternal and fetal prognosis.

The associated per operative gestures were tubal ligation and laparotomy for uterine rupture with a hysterectomy given the clinical picture of parturients. Resection of the tubals was performed in $07.1 \%, 0.4 \%, 0.7 \%, 5.2 \%$ respectively in 2004, 2007, 2008, 2009 and hysterectomy for uterine rupture was performed in $1.9 \%, 1.6 \%, 1.3 \%, 1.5 \%$ respectively in $2004,2007,2008,2009$. Table 9 shows the

Table 8. Maternal and fetal prognoses of cesarean sections at the Bougouni Reference Health Centre, Sikasso, Mali from 2004 to 2009.

\begin{tabular}{ccccccc}
\hline Years & $\begin{array}{c}2004 \\
\text { Effectifs \% }\end{array}$ & $\begin{array}{c}2007 \\
\text { Effectifs \% }\end{array}$ & $\begin{array}{c}2008 \\
\text { Effectifs \% }\end{array}$ & $\begin{array}{c}2009 \\
\text { Effectifs \% }\end{array}$ & Khi $^{2}$ & p \\
\hline Endometrites & $6(02.9 \%)$ & $7(02.8 \%)$ & $8(02.6 \%)$ & $4(01.5 \%)$ & 0.10 & 0.99 \\
Suppurations Parietal & $19(09.0 \%)$ & $20(08.1 \%)$ & $25(08.3 \%)$ & $20(07.1 \%)$ & $<5$ & 0.96 \\
No & $185(88.1 \%)$ & $219(89.0 \%)$ & $270(89.1 \%)$ & $244(91.0 \%)$ & 0.95 & 0.33 \\
Maternal prognosis & & & & & & \\
Living & $205(97.8 \%)$ & $240(97.5 \%)$ & $290(95.7 \%)$ & $267(99.6 \%)$ & $<5$ & 0.11 \\
Deceased & $5(02.4 \%)$ & $6(02.4 \%)$ & $13(04.3 \%)$ & $1(00.4 \%)$ & 0.43 & 0.03 \\
Fœtal prognosis & & & & & & \\
Living & $173(72.4 \%)$ & $191(77.6 \%)$ & $220(72.6 \%)$ & $210(78.3 \%)$ & 1.75 & 0.18 \\
Stillborn & $37(17.6 \%)$ & $55(22.4 \%)$ & $84(27.4 \%)$ & $58(21.7 \%)$ & 0.17 & 0.68 \\
Fresh & $33(15.7 \%)$ & $42(17.0 \%)$ & $68(22.3 \%)$ & $43(16.2 \%)$ & \\
Macerated & $4(01.9 \%)$ & $13(05.4 \%)$ & $16(05.1 \%)$ & $15(05.5 \%)$ &
\end{tabular}

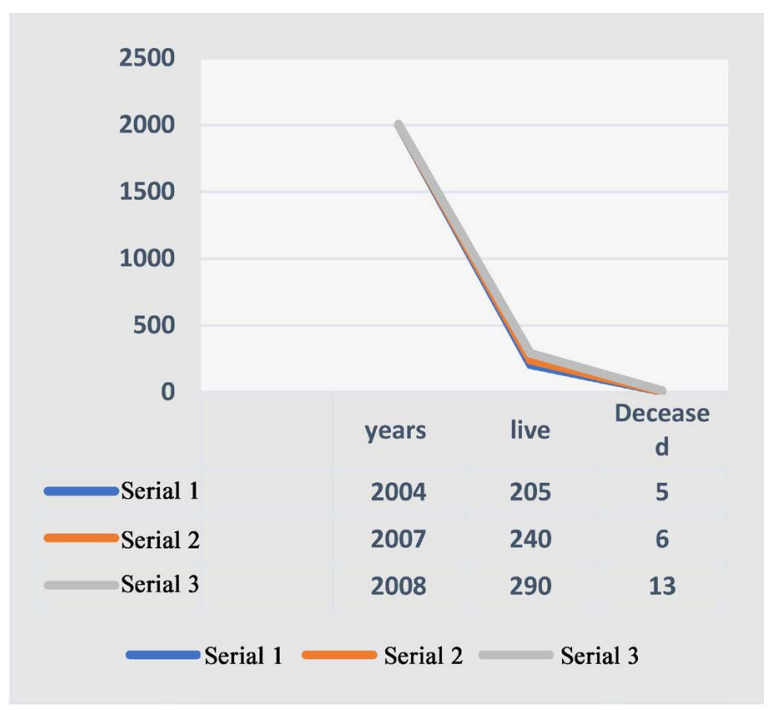

Figure 2. Maternal prognosis. 


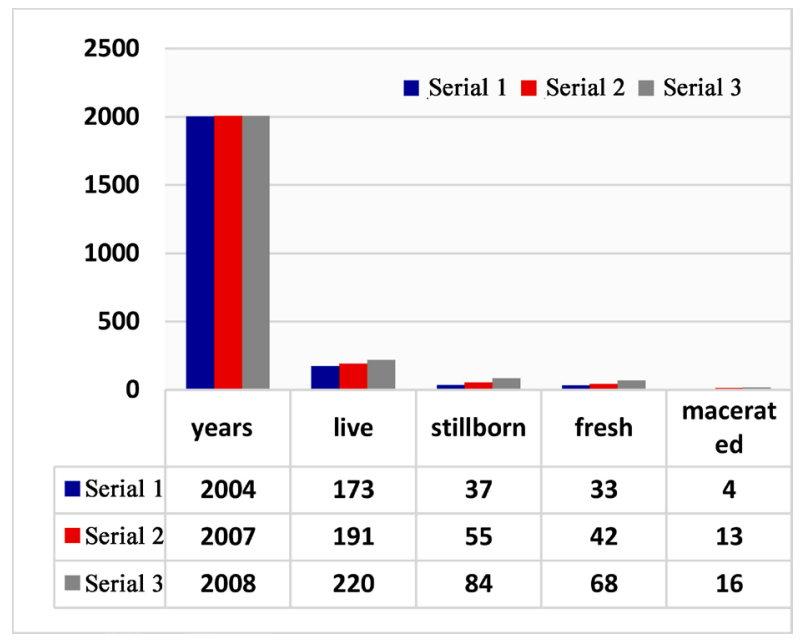

Figure 3. Fœtal prognosis.

Table 9. Distribution of parturients by per operative actions at the Bougouni Reference Health Centre, Sikasso, Mali from 2004 to 2009.

\begin{tabular}{|c|c|c|c|c|c|c|}
\hline Gestures Year & 2004 & 2007 & 2008 & 2009 & $\mathrm{Khi}^{2}$ & $\mathrm{p}$ \\
\hline Ligation of the tubes & $15(07.1 \%)$ & $1(00.4 \%)$ & $2(00.7 \%)$ & $14(05.2 \%)$ & 2.03 & 0.49 \\
\hline Laparotomy/Hysterectomy & $4(01.9 \%)$ & $4(01.6 \%)$ & $4(01.3 \%)$ & $4(01.5 \%)$ & 1.23 & 0.71 \\
\hline No & $191(91.0 \%)$ & $241(98.0 \%)$ & $297(98.0 \%)$ & $250(93.3 \%)$ & 0.67 & 0.41 \\
\hline Total & $210(100.0 \%)$ & $246(100.0 \%)$ & $303(100.0 \%)$ & $268(100.0 \%)$ & & \\
\hline
\end{tabular}

actions associated with caesarean section.

\section{Discussion}

\subsection{Epidemiological Aspects}

In the literature, various rates of cesarean section completion have been reported. In our series, cesarean section completion rates were $1.28 \%, 1.30 \%$, $1.53 \%, 1.32 \%$ respectively in $2004,2007,2008,2009$. Our rate is significantly lower than the optimal range set by the World Health Organization (WHO) which is $10 \%-15 \%$ [2]. In Mali, at the CHU Gabriel Touré de Bamako DIALLO C.H. [7] found $7.82 \%$ in 1989; CISSE H.G. [8] obtained $1.28 \%$ in 1988 in the same health structure. In 1996 at the hospital of Point "G" TEGUETE I. [9] found a rate of $24.05 \%$. SANOGO M. [10] found $18.49 \%$ in 2004 and $28.03 \%$ in 2006 at the Reference Health Centre in Koutiala, at the same time DIABY M. [11] obtained $10.8 \%$ (January to June 2005) before free and 10.3\% (July to December 2005) during the free. BERTHE Y. [12] recorded a rate of $18.6 \%$ in the obstetric gynecology department of the C.R.H. de Bouaké in Côte d'Ivoire. These rates are higher than those obtained during our study period. This is due to the completion of these caesarean sections in hospitals and reference health centres whose areas are larger than ours.

Socio-demographic characteristics: The average age was between 19 and 25 
years. The frequency of caesarean section in this age group was $34.1 \%$ in 2007 , $29.7 \%$ in $2008,38.8 \%$ in 2009 . Some authors found superior results than ours, KONATE M. [13] at the Gabriel Touré 82.1\%, TEGUETE I. [9] at The Hospital of Point "G" 79.3\%. On the other hand our rate is close to those reported by KOUYATE A.S. [14] which found $45.9 \%$ and SANOGO M. [10] which yielded $36.7 \%$ in Mali. It appears that the average ages corresponding to the peak of caesarean sections are those of the optimum reproductive period. In our study, we noted evacuations at $89.4 \%$ in $2007,70.0 \%$ in $2008,49.3 \%$ in 2009 . These rates are close to those obtained by DIALLO C. H. [7] or 71.87\%, TRAORE A. F. [15] or 91.9\%; TEGUETE I. [9] or $49.35 \%$.

With regard to reference/evacuations: The reference system experiencing functional failures, some of our patients were admitted directly. This predominance of evacuations found by most Malian authors is the work of a national health policy based on a referral/evacuation system with the aim of reducing maternal-neonatal morbidity. The average distance covered was 75.45 kilometers and the longest distance $150 \mathrm{~km}$.

The majority of our participants received 1 to 3 antenatal consultations. We achieved a rate of $66.3 \%$ in 2007 , respectively; $80.2 \%$ in $2008 ; 72.4 \%$ in 2009 . In 2004, the frequency of parturients who received 1 to 3 antenatal visits was $52.8 \%$. This rate is close to that obtained by DIABY M. [11] who found 52\%. These results are explained by the presence of many community health centers in the Bougouni health area.

\subsection{The Indications of the Caesarean Section}

During the study period, we performed 211 caesareans for preeclampsia; 179 caesareans for acute fetal suffering; 86 caesareans for prolonged delivery labour. In the absence of radiopelvimetry, only the clinic allowed us to diagnose the different types of bone dystocies encountered, which are among other things: the basins generally narrowed with frequencies of 3.3\%, $4.5 \%, 3.3 \%, 4.9 \%$ respectively in 2004, 2007, 2008, 2009 and immature basins with a rate of $6.7 \%, 0.0 \%$, $0.3 \%, 4.5 \%$ in 2004, 2007, 2008 and 2009 systematically led to a caesarean section. The boundary pools (after the failure of the work test) represented a rate of $0.0 \%, 0.7 \%, 1.5 \%$ in 2007,2008 and 2009 . Our rate is significantly lower than that reported by CISSE B. [16] at the Kayes Reference Health Centre, SIDIBE Y [1] at the Koro Reference Health Centre with a rate of $24.76 \%$ respectively; $25.27 \%$. These high rates of bone dystocies leading to caesarean section in these areas may be explained by: the high frequency of teen delivery associated with very frequent early marriages in these areas. Fetal appendix indications: during our study, retro-placental hematoma frequencies of $0.8 \%, 2.6 \%, 1.9 \%$ respectively were recorded. Our retro-placental hematoma rate of $4.3 \%$ in 2004 is lower than those obtained by some authors including SANOGO M. [10] $12.94 \%$ in 2006; TRAORE A. F. [15] 11.78\% and CAMARA S. [17] 12\%. Given the feasibility of ultrasound only on weekends, the precise diagnosis of third trimester 
haemorrhages is most often diagnosed in per operative procedure. We have no other explanation for this difference in outcome with ours. The placenta previa accounted for 7.6\%, 5.3\%, 9.9\%, 5.6\% respectively during the 2004 study period, 2007, 2008, 2009. Our different rates are higher than the rates of THIERNO M. [18] which found 2.5\%; RACINET [19] rated 3\% and CAMARA S. [17] who found $3.58 \%$. On the other hand, they are lower than those of DIALLO C. H. [7]; TRAORE A. F. [15] and TEGUETE I. [9] who obtained 8.12\% respectively; $8.68 \%$ and $9.03 \%$. In our series, the frequency of cesarean section indications for fetal suffering was $15.7 \% ; 13.8 \%, 20.5 \%, 18.7 \%$ respectively in 2004, 2007, 2008, 2009. Our rate is close to those obtained by TEGUETE I. [9] (16.06\%); CISSE B. [16] (18\%).

In the absence of electronic monitoring of the foetal heart, only the clinic allowed us to diagnose acute fetal suffering based on changes in the colour of the amniotic fluid and/or foetal heart rate to obstetrical stethoscope.

The indications of caesarean section related to the genital state: the bi-scarred uterus represented $4.3 \%$ in 2004; $2 \%$ in $2007 ; 6.3 \%$ in 2008 ; $7.5 \%$ in 2009 . These rates are close to those obtained by SANOGO M. [10] and SIDIBE Y. [1] with $6.71 \%$ and $3.30 \%$ respectively. A doubly scarred uterus associated with any other risk factor for dystocia birth puts the old scar at risk of disunity. To avoid this tragedy, the obstetrician resorts to caesarean section, hence the increase in his rate among the indications of this intervention. We noted 16 cases of uterine rupture at a frequency of $7.6 \%$ and $8.9 \%, 9.9 \%, 9.7 \%$ respectively in 2004, 2007, 2008, 2009. These rates are higher than those obtained by TRAORE Y. [20] in 2008 and are close to that of SANOGO M. [10] during the second half of 2005 with a frequency of $6.3 \% ; 08 \%$. On the other hand, SIDIBE Y. [1] found in 2004 a higher rate than ours with a frequency of $12.7 \%$. Several factors come into play for the occurrence of these extreme emergencies. As the various outlying health areas are too far from the reference health centre, the deplorable state of the roads, especially during the rainy season, has been blamed in the prolonged period of evacuations of these parturients. The insufficient number of ambulances to transport them, the insufficient training of some health workers to detect emergencies also lead to a delay in the decision to evacuate. The clandestine and abusive use of oxytocins and often even the husband's refusal to accept the reference decision immediately are among other causes of uterine rupture. Other caesarean section indications were shoulder presentations, cord providence, providences of the limbs; loaded obstetric history, genital prolapse. During the study period, the rates found in our study are lower than that found by SIDIBE Y. [1] with a rate of 59.3\%. Some indications of caesarean section dependent on the expectation of the obstetrician may explain this difference in rate with ours.

Per operatively associated gestures: Our study reports rates of tubal resection ligation ranging from $0.4 \%-7.1 \%$ depending on the years to $1.3 \%-1.9 \%$ hysterectomy in the context of laparotomy for uterine rupture. Our rates of tubal ligation and resection and hysterectomy are significantly lower than those ob- 
tained by TRAORE Y. [20] and SANOGO M. [10] with rates of $28.57 \%$ and $7.1 \%$ respectively; $85.71 \%$ and $14.28 \%$. In carrying out these gestures, many parameters must be taken into account: anatomical lesions, the general condition of the patient, his age, his parity, his level of education, his desire to procreate, the experience of the anaesthetist and that of the surgeon.

In terms of maternal-fetal prognosis: The surgical consequences were simple in $90 \%$ of our patients. However, infectious complications of endometritis and parietal suppurations were noted. Thus in 2004, the rate of endometritis was $2.90 \%$ and that of parietal suppuration was $9 \%$, whereas in 2009 the rate of endometritis was $1.5 \%$ and that of parietal suppuration was $7.1 \%$. Our parietal suppuration rate is higher than those found by SIDIBE Y. [1] and SANOGO M. [10] with a rate of $5.49 \%$ and $2.99 \%$ respectively. We noted maternal deaths with a rate of $2.4 \%, 2.4 \%, 4.3 \%, 0.4 \%$ respectively in 2004, 2007, 2008, 2009. The rates for 2007, 2008 are higher than those obtained by SANOGO M. [10], SIDIBE Y. [1] and DIABY M. [11] at a rate of $1.49 \% ; 1.10 \%$ and $1.10 \%$.

We are seeing a gradual decrease in the maternal death rate in 2009 . This decrease is statistically significant [Table $8, \mathrm{P}-0.03$ ]. These deaths are mainly due to hemorrhages in the third trimester of pregnancy.

And stillbirth rates were $17.6 \%, 22.4 \%, 27.4 \%, 21.7 \%$ respectively in 2004 , 2007, 2008, 2009; we are also seeing an increase in the number of newborns alive. However, the neonatal death rate remained flat (Table 8).

The delay in making evacuation decisions, the delay in the care of patients, the long time to transport these patients to the reference health centre because of the condition of the journey, the surgical team being composed of a single anaesthetist and a block assistant, the lack of paediatric service for the resuscitation of newborns are considered factors that can hinder the good prognosis of this intervention at the reference health center of Bougouni despite the institution of the free. For caesarean kits: in 1 case/100 the caesarean kit was not available at the time of the caesarean section. This rupture of the caesarean kits delays management with adverse consequences for the mother and fetus.

Length of hospitalization: The average length of hospitalization was 10 days with extremes of 5 to 25 days. Our study noted that there is a statistically significant relationship between length of hospitalization and free caesarean section [Table 7, P-0.01]. This value is close to those obtained by SYLLA C. [21] at C $\mathrm{H}$ U Gabriel TOURE in 2004 and SIDIBE Y. [1] at the Koro Reference Health Centre with an average duration of 11 days each. In the absence of post-operative complications, the average length of hospitalization should not exceed 10 days.

Difficulties free caesarean section: The free caesarean section has improved the maternal-fetal prognosis. However, some difficulties hinder its smooth running, including: the difficulty of communication in areas not covered by a mobile telephone network requiring the technical directors of the centres to travel miles in order to reach the reference health centre, the weak community organization to support village participants in access to community health centres or 
referral health centres, the organisation of the referral/evacuation system to enable the rapid management of obstetrical emergencies, the late use of parturients to care facilities resulting in a high rate of deaths born, the delay in obtaining adequate care at the level of referral structures during on-call hours.

\section{Conclusion}

Free caesarean section would be a factor in improving the maternal-fetal prognosis.

\section{Conflicts of Interest}

The authors declare no conflicts of interest regarding the publication of this paper.

\section{References}

[1] Sidibé, Y. (2008) Impact of Free Caesarean Section at the Koro Circle Reference Health Centre. Thesis Med., FMPOS, Bamako, 474.

[2] O.M.S. (1996) Perinatal Mortality; Summary of the Available Data. News Release 46, Geneva, 1-2.

[3] Merger, L. and Melchior, J. (1989) Obstetrics Precise. Masson, Paris, 618-627.

[4] Thoulon, J.M. (1979) The Cesarean Sections. Encycl. Med. Chir., Paris Obstetrics, 5102A-10.

[5] National Survey of the Provision of Emergency Obstetric and Neonatal Care in Mali in 2003. Report.

[6] A Guide to the Implementation of Free Caesarean Section. August 2005, No. 4.

[7] Diallo, C.H. (1990) Contribution to the Study of Caesarean Section. About a Continuous Series of 160 Cases in the Department of Gynecology and Obstetrics of the Gabriel Touré Hospital from October 1, 1989 to September 30, 1990. Thesis Med., Bamako, No. 37.

[8] Cissé, H.G. (1988) Contribution to the Study of DPPNI and Its Serious Forms. Thesis Med., Bamako MALI, No. 15.

[9] Tegueté, I. (1996) Clinical and Epidemiological Study of Caesarean Section at the Maternity Ward of the National Hospital of Point "G" 1991-1993. Thesis Med., Bamako, No. 17.

[10] Sanogo, M. (2008) Impact of Free Caesarean Section at the Koutiala Reference Health Centre. Thesis Med., FMPOS, Bamako, No. 472.

[11] Diaby, M. (2006) Study of Caesarean Section at the Maternity Ward of the Reference Health Centre in Commune I of Bamako District from 1 Jan. to 31 Dec. 2005. Thesis Med., Bamako, No. 286.

[12] Berthe, Y. (1992) Fetal-Maternal Prognosis in Caesarean Deliveries. About 218 Cases Recorded in the Obstetric Gynecology Department of the C.H.R. of Bouaké in One Year. Medical Thesis, Abidjan, No. 623.

[13] Konate, M. (2001) The Study of Caesarean Sections in the Obstetric Gynecology Department over a Period of 5 Years at the Gabriel Touré Hospital. Medical Thesis, Bamako Mali, Number 20.

[14] Kouyaté, A.S. (1995) The Demographic and Obstetric Aspects of Post-Cesarean Infectious Complications in the Gynecology and Obstetrics Department of the H.G.T. 
Med. Thesis, Bamako Mali, No. 42.

[15] Traoré, A.F. (1989) Study of Obstetric Complications and Maternal Mortality at H.G.T. Maternity. Thesis Med., Bamako MALI, No. 46.

[16] Cissé, B. (2001) The Caesarean Section at the Maternity Ward of Kayes Hospital about 215 Cases. Medical Thesis, Bamako, 37 p.

[17] Camara, S. (1998) Césarienneer: Factor in Reducing Morbidity and Maternal Mortality at the Ignace Deen University Hospital in Conakry (GUINEE). Thesis Medicine, No. 45.

[18] Thiero, M. (1995) Emergency Medical Evacuations in Obstetrics at Gabriel Touré Hospital about 160 Cases. Thesis Med.; No. 20.

[19] Racinet, C. and Favier, M. (1984) The Caesarean Section. Masson, Paris.

[20] Traoré, Y., Mounkoro, N., Traoré Dicko, F., Tegueté, I., Thera, A., Djiré, Y.M., Sissoko, A., Diallo, A., Bagayoko, M., Dolo, T., Sanogo, A.C., Sy, A.S. and Dolo, A. (2009) Uterine Rupture in Rural Mali. Annals of SOGGO, 4, 12.

[21] Sylla, C. (2004) Post Partum Endometritis in the Obstetric Gynecology Department of Gabriel Touré Hospital. Thesis Medicine, Bamako, Mali, No. 17. 